\title{
Decreased Pretreatment Amygdalae Serotonin Transporter Binding in Unipolar Depression Remitters: A Prospective PET Study
}

\author{
Mala R. Ananth ${ }^{1}$, Christine DeLorenzo ${ }^{2-4}$, Jie Yang ${ }^{5}$, J. John Mann ${ }^{5}$, and Ramin V. Parsey ${ }^{2,3}$ \\ ${ }^{I}$ Department of Neurobiology and Behavior, Stony Brook University, Stony Brook, New York; ${ }^{2}$ Psychiatry, Stony Brook University, \\ Stony Brook, New York; ${ }^{3}$ Biomedical Engineering, Stony Brook University, Stony Brook, New York; ${ }^{4}$ Department of Psychiatry, \\ Columbia University, College of Physicians and Surgeons, New York, New York; and ${ }^{5}$ Family, Population and Preventative Medicine, \\ Stony Brook University, Stony Brook, New York
}

Major depressive disorder (MDD) is a debilitating condition that affects over 14 million Americans. Remission occurs only in a minority of individuals after first-line antidepressant treatment ( $35 \%)$; predictors of treatment outcome are therefore needed. Using PET imaging with a radiotracer specific for the serotonin transporter (5-HTT), ${ }^{11} \mathrm{C}-\mathrm{McN} 5652$, we found that patients with MDD who did not achieve remission after 12 mo of naturalistic treatment had lower pretreatment midbrain and amygdala binding than healthy volunteers. Here, using a superior 5 -HTT tracer, ${ }^{11} \mathrm{C}$-DASB, we repeated this study with a prospective design with $8 \mathrm{wk}$ of standardized treatment with escitalopram. As this same cohort also underwent ${ }^{11} \mathrm{C}$-WAY100635 scans (serotonin-1A receptor $\left[5-\mathrm{HT}_{1 \mathrm{~A}}\right]$ ), we examined whether using both pretreatment $5-\mathrm{HTT}$ and $5-\mathrm{HT}_{1 \mathrm{~A}}$ binding could improve prediction of posttreatment remission status. Methods: Thirty-one healthy controls (Hamilton Depression Rating Scale-24 item [HDRS-24] = 1.7) and 26 medication-free patients with MDD (HDRS-24 = 24.8) underwent PET scanning using ${ }^{11} \mathrm{C}$-DASB. MDD subjects then received $8 \mathrm{wk}$ of standardized pharmacotherapy with escitalopram. The relationship between pretreatment binding and posttreatment clinical status was examined. Arterial blood samples were collected to calculate the metabolite-corrected arterial input function. The outcome measure was $V_{T} / f_{P}\left(V_{T}\right.$ is volume of distribution in region of interest, $f_{P}$ is free fraction in plasma). Remission was defined as a posttreatment depression score of less than 10 as well as $50 \%$ or more reduction in the score from baseline, resulting in 14 nonremitters (HDRS-24 = 17.6) and 12 remitters (HDRS- $24=5.3$ ). Results: A linear mixedeffects model comparing group differences in the a priori regions of interest (amygdala and midbrain) revealed a significant difference in amygdala binding between controls and remitters $(P=0.03$, unadjusted), where remitters had an $11 \%$ lower amygdala binding than controls. Differences in amygdala binding between remitters and nonremitters approached significance $(P=0.06)$. No additional differences were found between any groups (all $P>0.05$ ). Additionally, we found no relationship between pretreatment amygdala binding and posttreatment depression score, and were unable to predict posttreatment depression severity using both pretreatment $5-\mathrm{HTT}$ (in the amygdala) and $5-\mathrm{HT}_{1 \mathrm{~A}}$ binding (in the raphe). Conclusion: These results suggest 5-HTT amygdala binding should be examined further, in conjunction with other measures, as a potential biomarker for remission after standardized escitalopram treatment.

Received Jan. 8, 2017; revision accepted Jul. 25, 2017.

For correspondence or reprints contact: Mala Ananth, 101 Nichols Rd., HSC T-010, Rm. 41N, Stony Brook University, Stony Brook, NY 11794.

E-mail: mala.ananth@stonybrook.edu

Published online Sep. 21, 2017.

COPYRIGHT @ 2018 by the Society of Nuclear Medicine and Molecular Imaging.
Key Words: molecular imaging; PET; other; depression; PET imaging; prediction; remission; serotonin transporter

J Nucl Med 2018; 59:665-670

DOI: 10.2967/jnumed.117.189654

$\mathbf{M}$ ajor depressive disorder (MDD) is a debilitating condition that affects over 14 million Americans $(1,2)$ and is now the second leading cause of disability worldwide $(3,4)$. MDD is a heterogeneous disorder comprised of clusters of symptoms; treating this disorder is, therefore, complex. Optimizing medication treatment is challenging and involves weeks of trial and error, which is stressful, uncomfortable, and sometimes life-threatening for patients. Remission occurs in a minority of individuals after first-line antidepressant treatment $(30 \%-45 \%)(5)$, whereas $10 \%-30 \%$ of patients will not respond to any treatment $(5,6)$. What is needed is a better understanding of the biology underlying this disorder, allowing for patient-specific treatment selection and improved response rates.

The serotonergic system has been implicated in the pathophysiology of depression and is a major target of antidepressant treatment $(7,8)$. 5-HTT (serotonin transporter), the target of selective serotonin reuptake inhibitors (SSRIs), has been examined in MDD extensively (9-13) in postmortem and in vivo investigations. A metaanalysis including 25 in vivo studies found reduced 5-HTT binding in both the midbrain and the amygdala as well as the striatum, but not in the thalamus or hippocampus, in MDD compared with controls (9). Evaluations of postmortem studies also revealed decreases in overall 5-HTT levels in the amygdala and striatum (though these were few and did not achieve statistical significance), but not in the frontal cortex, brain stem, or hippocampus (9). Furthermore, low levels of 5-HTT binding in the amygdala have been associated with depression and anxiety (14).

A major advance in the study of psychiatric illness is the use of neuroimaging techniques. Using PET imaging with a 5-HTT tracer, ${ }^{11} \mathrm{C}-\mathrm{McN} 5652$, our group has found that 5-HTT binding differs between healthy controls and MDD patients in a depressive episode (11). Additionally, we found that nonremission from MDD after 12 mo of naturalistic treatment was associated with lower pretreatment midbrain and amygdala binding as compared with controls. When using a superior 5-HTT tracer $(15,16),{ }^{11} \mathrm{C}$-DASB, we were unable to replicate the differences between controls and 
patients with MDD (10); however, we found that suicide attempters had lower midbrain binding than nonattempters and controls. We postulated that perhaps the differences we initially observed within the MDD group may have been due to a heterogeneous population comprised of multiple clinical characteristics.

Here, we improve on the previous (naturalistic) study design using standardized treatment with SSRI escitalopram to investigate whether pretreatment 5-HTT binding $\left({ }^{11} \mathrm{C}\right.$-DASB $)$ is predictive of subsequent nonremission in the midbrain and amygdala. These previously examined regions of interest (ROIs) have been identified in several studies, highlighting their importance in the pathophysiology of MDD and treatment response. Additionally, we have examined serotonin-1A receptor $\left(5-\mathrm{HT}_{1 \mathrm{~A}}\right)$ binding in this same cohort $(17)$ and found pretreatment raphe $5-\mathrm{HT}_{1 \mathrm{~A}}$ binding significantly differs between remitters and nonremitters (where remitters had higher 5- $\mathrm{HT}_{1 \mathrm{~A}}$ binding) yet was unable to predict posttreatment depression severity (17). Here we examine the potential of $5-\mathrm{HT}_{1 \mathrm{~A}}$ and 5-HTT binding to predict posttreatment depression severity.

\section{MATERIALS AND METHODS}

\section{Subjects/Treatment}

This study was approved by the Institutional Review Boards of the New York State Psychiatric Institute and Columbia University Medical Center. Thirty-one healthy volunteers and 26 subjects who met the DSM-IV criteria for MDD were included in this study. Data from all controls and 24 of the 26 MDD subjects were reported in a previous study using a different PET tracer, ${ }^{11} \mathrm{C}$-WAY10035 (17). Recruitment, consent, and eligibility were as previously described (17).

\section{Clinical Procedures}

MDD subjects were not taking medication $(n=19)$ or were weaned from ineffective medication $(n=6)$ before enrollment into the study (one subject's previous medication status was unknown). After baseline PET and MRI scans, treatment was initiated with escitalopram. At week 4, the escitalopram dose was increased for nonresponders $(<50 \%$ decrease in Hamilton Depression Rating Scale [HDRS]), whereas responders remained at $10 \mathrm{mg} / \mathrm{d}$. At week 6 , any subject who was a nonremitter ( $>10$ HDRS) and was still taking $10 \mathrm{mg}$ daily had the escitalopram dose increased to $20 \mathrm{mg}$ per day. HDRS-24 was used to assess depression severity at baseline and at $8 \mathrm{wk}$. Remission status was defined as a $50 \%$ or more decrease in HDRS-24 score as well as a final HDRS-24 score of less than 10. Using these criteria, we classified 12 subjects as remitters and 14 subjects as nonremitters.

\section{Radiochemistry}

${ }^{11} \mathrm{C}$-DASB was prepared as previously described (18).

\section{PET Scanning Protocol}

PET scanning was conducted as previously described (19). In brief, PET images were acquired on an ECAT EXACT HR + camera (Siemens/ CTI). After a 10-min transmission scan, ${ }^{11} \mathrm{C}$-DASB was injected as an intravenous bolus, and emission data were collected for $100 \mathrm{~min}$.

\section{Image Processing}

Image analysis was performed as previously described $(10,12)$. In brief, motion correction of PET data was performed where frame-byframe rigid-body registration was performed to a reference frame. A mean of the motion-corrected frames was then coregistered to the MRI. ROIs were hand drawn on the MR images of 18 healthy subject by experienced technicians trained to reliably approximate these regions using brain atlases $(20,21)$ and published reports $(22,23)$. To generate probabilistic ROIs, each subject's MR image was preprocessed, and each of the 18 template images was registered with the Automated
Registration Toolbox to the subject's brain. The probability of a regional label was defined as the percentage of the 18 templates that assign the same regional label to that voxel.

\section{Quantitative Analysis}

Arterial samples were collected continuously for the first $4 \mathrm{~min}$, and manually thereafter (every $10 \mathrm{~s}$ until 2 min, every $20 \mathrm{~s}$ until 4 min, every $2 \mathrm{~min}$ until $8 \mathrm{~min}$, every $4 \mathrm{~min}$ until $20 \mathrm{~min}$, and every $10 \mathrm{~min}$ until the end of the scan). The metabolite-corrected arterial input function was calculated by multiplying interpolated plasma radioactivity counts by the percentage parent compound and was fit using a straight line before the peak and the sum of 3 exponentials after the peak (19). The fitted values were used as the metabolite-corrected arterial input function. The volume of distribution in a region of interest $\left(\mathrm{V}_{\mathrm{T}}\right)$ estimates were obtained using likelihood estimation in graphical analysis and, with the arterial analysis, were used to calculate our primary outcome measure: $\mathrm{V}_{\mathrm{T}}$ /free fraction in plasma $\left(\mathrm{f}_{\mathrm{P}}\right)(10,19,24,25)$. Using this measure, estimated that binding does not rely on a reference region. It has been shown that an optimal reference region does not exist for ${ }^{11} \mathrm{C}-\mathrm{DASB}$ (26). Standard errors were computed for each estimated $\mathrm{V}_{\mathrm{T}}$ value using a bootstrapping algorithm that accounts for errors in plasma, metabolite, and brain data (27).

\section{Voxelwise Average Images}

$\mathrm{V}_{\mathrm{T}} / \mathrm{f}_{\mathrm{P}}$ binding maps were calculated on a voxel-by-voxel level using empiric Bayesian estimation in graphical analysis, as previously described $(28,29)$. For display, images were equally thresholded and displayed at the plane of the amygdala.

\section{Statistical Analysis}

Group comparisons of $\mathrm{V}_{\mathrm{T}} / \mathrm{f}_{\mathrm{P}}$ between remitters, nonremitters, and controls were performed using a linear mixed-effects model with subject as the random effect and diagnosis, subject group, and age as covariates. The midbrain and amygdala were a priori ROIs. Additionally, a linear mixed model was used to determine the potential of pretreatment ${ }^{11} \mathrm{C}$-DASB binding covaried by pretreatment HDRS-24 to predict posttreatment HDRS-24. As a secondary analysis, we examined 4 additional ROIs (thalamus, dorsal putamen, hippocampus, and anterior cingulate cortex).

In the same cohort, our group found significantly higher pretreatment 5 - $\mathrm{HT}_{1 \mathrm{~A}}$ binding in the raphe of remitters as compared with nonremitters (17), though we were unable to use $5-\mathrm{HT}_{1 \mathrm{~A}}$ binding to predict posttreatment HDRS. Our group has previously shown that there is no correlation between 5-HTT binding and 5- $\mathrm{HT}_{1 \mathrm{~A}}$ binding (25), and accordingly we did not find a correlation here. This suggests that ${ }^{11} \mathrm{C}$-WAY-100635 and ${ }^{11} \mathrm{C}$-DASB quantification may provide complementary information. We postulated that a combined model using both raphe $5-\mathrm{HT}_{1 \mathrm{~A}}$ and amygdala 5-HTT binding may better predict remission than either measure alone. Linear regression was used to determine whether pretreatment raphe $\left(5-\mathrm{HT}_{1 \mathrm{~A}}\right)$ binding and amygdala (5-HTT) binding, covaried for pretreatment HDRS-24, predicted posttreatment HDRS-24.

To allow for a test in proportional differences, to stabilize variance across regions, and to alleviate skewness, we and other groups used logtransformed data in all analyses involving multiple regions $(10,11,26)$. Data presented graphically are displayed as actual (nonlog-transformed) data. Reported $P$ values are unadjusted for multiple comparisons. Statistical tests were performed in SAS 9.3 (SAS Institute Inc.) and R 2.1.0 (http://cran.r-project.org)

\section{RESULTS}

\section{Sample Characteristics}

Summary statistics for clinical variables are presented in Table 1. No differences in HDRS-24 pretreatment score were found between the remitters and nonremitters. Significant differences in $f_{P}$ $(P=0.02)$ and trending differences in reference region $(P=0.07)$ binding were found between controls and remitters. 
TABLE 1

Sample Characteristics

\begin{tabular}{|c|c|c|c|c|}
\hline Characteristic & Control & MDD nonremitter & MDD remitter & $P$ \\
\hline Sample size & 31 & 14 & 12 & - \\
\hline Age $(y)$ & $32.62 \pm 11.27$ & $37.03 \pm 13.47$ & $36.67 \pm 13.48$ & $0.54^{\star}$ \\
\hline HDRS-24 pretreatment & $1.68 \pm 2.41$ & $25.43 \pm 2.26$ & $24.08 \pm 6.23$ & $0.59^{\dagger}$ \\
\hline HDRS-24 posttreatment & - & $17.57 \pm 3.90$ & $5.33 \pm 3.06$ & $0.001^{\dagger}$ \\
\hline HDRS-17 scores (inclusion criteria) & $1.42 \pm 1.28$ & $19.07 \pm 4.60$ & $19.08 \pm 5.03$ & $1.0^{\dagger}$ \\
\hline Beck Depression Inventory & $1.29 \pm 1.69$ & $26.71 \pm 10.04$ & $22.42 \pm 10.47$ & $0.30^{\dagger}$ \\
\hline Beck Hopelessness Scale & $1.32 \pm 1.87$ & $11.36 \pm 5.25$ & $7.8 \pm 6.38$ & $0.26^{\dagger}$ \\
\hline Age of onset & - & $25.5 \pm 13.5$ & $24.17 \pm 12.61$ & $0.66^{\dagger}$ \\
\hline Number of depressive episodes & - & $13.85 \pm 30.50$ & $19.33 \pm 37.47$ & $0.69^{\dagger}$ \\
\hline Number of first-degree relatives with depression & $4 \pm 2$ & $4 \pm 2$ & $3 \pm 2$ & $0.48^{*}$ \\
\hline Percentage with comorbid anxiety & - & $7 \%$ & $8 \%$ & $0.96^{\dagger}$ \\
\hline Percentage female & $52 \%$ & $71 \%$ & $58 \%$ & $0.47^{\dagger}$ \\
\hline Percentage of smokers & 6.5 & 25 & 7.1 & $0.25^{\star}$ \\
\hline Free fraction $\left(f_{P}\right)$ & $0.12 \pm 0.3$ & $0.1 \pm 0.01$ & $0.1 \pm 0.02$ & $0.02^{*}$ \\
\hline Reference region binding & $10.50 \pm 2.19$ & $10.64 \pm 1.41$ & $9.41 \pm 1.39$ & $0.07^{*}$ \\
\hline
\end{tabular}

*Statistics comparing all groups.

${ }^{\dagger}$ Statistics comparing nonremitters and remitters, only.

\section{5-HTT Binding in Remission}

Remitters had lower 5-HTT pretreatment binding $\left(\mathrm{V}_{\mathrm{T}} / \mathrm{f}_{\mathrm{P}}\right)$ than controls in the amygdala $(P=0.03$, unadjusted; Figs. 1 and 2$)$. Remitters had a trend of lower 5-HTT pretreatment binding in the amygdala than nonremitters, $(P=0.06$, unadjusted). No differences in amygdala binding were found between nonremitters and controls $(P=0.97)$, or in the midbrain, thalamus, dorsal putamen, hippocampus, or anterior cingulate cortex between any groups $(P>0.05)$.

\section{Pretreatment Binding to Predict Posttreatment}

\section{Depression Severity}

Using a linear mixed model, we did not find a significant relationship between 5-HTT amygdala binding and posttreatment HDRS-24 score $(P=0.39)$. Linear regression revealed no

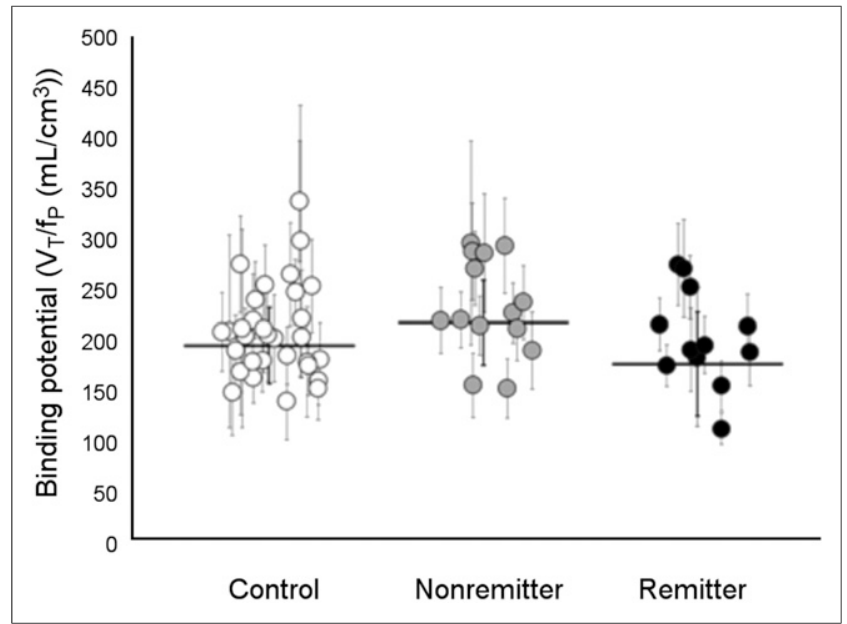

FIGURE 1. Comparison of binding potential by group in amygdala; weighted means and weighted errors are shown with black lines. *Significant difference between control and remitter where $P<0.05$. correlation of raphe $5-\mathrm{HT}_{1 \mathrm{~A}}$ and amygdala 5-HTT binding in predicting posttreatment HDRS-24 score $(P=0.24)$.

\section{DISCUSSION}

Pretreatment 5-HTT Amygdala Binding Differs in Remission

We observed lower pretreatment 5-HTT binding in the amygdalae of remitted patients than healthy controls, which remained a trend after correction for multiple comparisons. There was a trend toward lower 5-HTT binding in remitters than nonremitters. The lack of significance between remitters and nonremitters may have been due to the large variance and modest sample size in these groups. Additionally, we found no difference in midbrain, dorsal putamen, thalamic, hippocampal, and anterior cingulate cortex binding between any groups. These findings are at odds with previous results from Kuyaga et al., who reported higher pretreatment diencephalonic (midbrain subdivision) 5-HTT binding (SPECT) associated with improved response to acute fluoxetine or paroxetine treatment (4 and $6 \mathrm{wk}$, respectively) (30). It is possible that the discrepant findings are due to the use of ${ }^{123}$ I- $\beta$-CIT, a SPECT tracer known to bind to both 5-HTT and DAT (compared with ${ }^{11} \mathrm{C}$-DASB in the current study), as well as the use of an outcome measure that relies on reference region. These findings are in partial agreement with a metaanalysis that showed consistent reduction in 5-HTT levels in the amygdala in depression (31).

\section{Pretreatment Binding to Predict Posttreatment Depression Severity}

We did not find a relationship between pretreatment 5-HTT amygdala binding and posttreatment HDRS-24. Additionally, we were unable to predict depression severity using the $5-\mathrm{HT}_{1 \mathrm{~A}}$ and 5-HTT combined data. These results are unsurprising as pretreatment 5-HTT amygdala binding between nonremitters and remitters was not significantly different. The addition of 5-HTT amygdala binding was, therefore, unable to strengthen the model. Interestingly, 


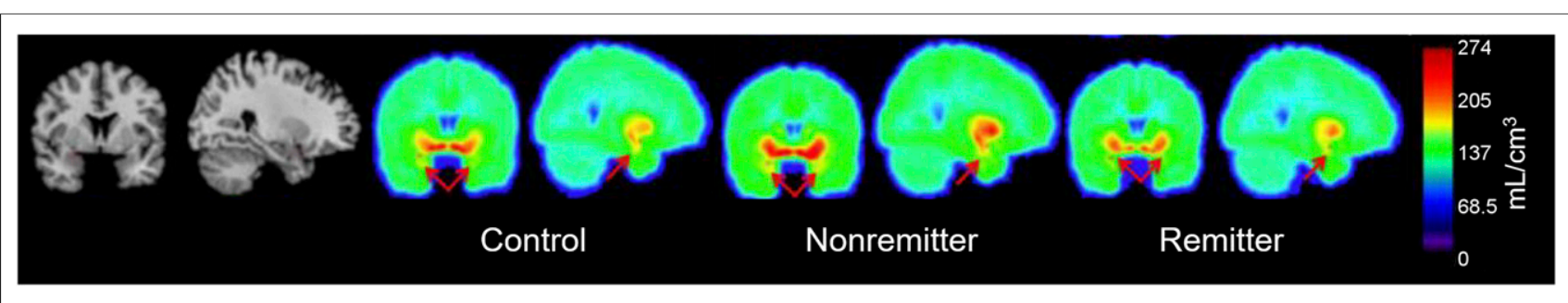

FIGURE 2. Averaged voxel images of control, remitter, and nonremitter $5-H T T$ binding $\left(\mathrm{V}_{\mathrm{T}} / \mathrm{f}_{\mathrm{P}}\right)$ at plane of amygdala (red arrows).

Lazenberger et al. found that pretreatment 5-HTT binding ratios (amygdala to raphe nucleus) were able to predict $3 \mathrm{wk}$ posttreatment response using ${ }^{11} \mathrm{C}$-DASB (32). It is possible this discrepancy is due to the different measure that was used (ratio of amygdala to raphe nucleus) and the length of treatment before assessing outcome.

\section{Choice of Binding Potential Measure}

Here, we use the outcome measure $\mathrm{V}_{\mathrm{T}} / \mathrm{f}_{\mathrm{P}}$, which is conservative by not correcting for reference region binding and normalizes the data by $f_{\mathrm{P}}$. We chose this outcome measure for a few reasons. We report significantly lower free fraction in remitters than controls. This could be due to an elevation in tracer binding to peripheral plasma proteins, and could result in inaccurate 5-HTT density determination, as subjects with greater $f_{p}$ could have higher binding because more tracer is free to bind. An outcome measure that normalizes for free fraction differences at the individual level is needed.

We found that the difference in reference region binding between controls and remitters approaches significance, where remitters have lower reference region binding than controls. This further corroborates that the reference region (cerebellar gray matter) may not be devoid of specific binding (11). In this case, correcting $\mathrm{V}_{\mathrm{T}}$ by reference region binding could incorrectly estimate $V_{T}$.

Differences in free fraction and reference region binding have been observed in other studies that use different tracers (33). These measures alone cannot provide us with any information about the specific neurotransmitter abnormalities in MDD and cannot be used as a surrogate for binding studies.

\section{Interpretation of Findings}

We previously found higher raphe $5-\mathrm{HT}_{1 \mathrm{~A}}$ binding in remitters than controls and postulated that higher raphe $5-\mathrm{HT}_{1 \mathrm{~A}}$ levels at baseline would cause low basal firing rate (17). Normal 5-HT transmission in the amygdala is thought to inhibit amygdala activity via activation of $\gamma$-aminobutryic acid (GABA) interneurons (34). A reduced basal firing rate may remove amygdala inhibition, resulting in hyperactivity. Hyperactivity in the amygdala has been shown to increase the salience of an aversive event and is observed in depression and anxiety (35-40).

In this study, we showed that this same cohort of subjects (remitters) has lower 5-HTT binding in the amygdala. We hypothesized that lower amygdala binding in the remitter group might be correlated with decreased 5-HTT levels. As partial validation of this, 5-HTT null mice do exhibit reduced firing rate in dorsal raphe neurons as compared with control mice (41), further supporting our previous hypothesis that low 5-HTT levels could contribute to a low basal firing rate.

Postmortem studies have found decreased 5-HTT levels in MDD (42-45). Interestingly, lower 5-HTT binding in the amygdala has been associated with high anxiety (46). Functional MRI studies have revealed amygdala hyperactivity in response to negative stimuli $(36,47)$, similar to hyperactivity seen in subjects with MDD. Importantly, SSRI administration has been shown to alleviate this hyperactivity $(36-38,48)$.

With acute SSRI administration raphe autoreceptors, sensitive to the increase in serotonin, are thought to decrease serotonergic firing. With repeated administration, the desensitization of autoreceptors may enhance serotonin release (49). An increase in transmission, coupled with previously low levels of 5-HTT, could enhance the effects of serotonin; with saturated transporters, prolonged effects of 5-HT are possible in the synapse. These data suggest that patients with lower amygdala 5-HTT levels coupled with elevated raphe $5-\mathrm{HT}_{1 \mathrm{~A}}$ levels-patients with greater serotonergic abnormality - are more likely to benefit from serotonergic intervention (escitalopram). Interestingly, 1 study reported that remitted depressed individuals did not have lower 5-HTT binding in the amygdala and several other regions than controls, suggesting that these may not be trait properties, and instead state markers of a subset of the MDD population (50).

We found that MDD nonremitters, after 1 y of naturalistic treatment, had lower pretreatment amygdala binding than controls (12). These discrepant findings of lower amygdala binding in nonremission (previous study (12)) and remission (current study) could be due to study design (naturalistic vs. prospective), length after which treatment outcome was assessed (1 y vs. $8 \mathrm{wk}$ ), radiotracer $\left({ }^{11} \mathrm{C}-\mathrm{McN} 5652\right.$ vs. ${ }^{11} \mathrm{C}$-DASB), and possible differences in the sampling of depressed patients.

This group of MDD subjects who remit after $8 \mathrm{wk}$ of escitalopram treatment have higher raphe $5-\mathrm{HT}_{1 \mathrm{~A}}$ levels and lower amygdala 5-HTT levels. It is unclear which is primary, though Gobbi et al. showed a decreased firing rate in dorsal raphe nuclei in 5-HTT null mice; thus, it is possible that 5-HTT may play a role in the regulation of 5-HT neurotransmission (41). Either way, these findings suggest that subjects with greater serotonergic abnormality benefit most from serotonergic intervention. As nonremitters do not exhibit serotonergic abnormalities, it is possible they require nonserotonergic intervention. We postulate that amygdala hyperactivity in nonremitters may be mediated by deficient GABAergic transmission and an inability to maintain sufficient control in the amygdala. There exists considerable evidence for low GABAergic transmission as a feature of MDD as well as anxiety and mood disorders $(51,52)$. Alternatively, it is possible that hyperactivity in the amygdala is a result of elevated glutamatergic transmission (35), as there is increasing support for glutamatergic intervention in psychiatric disorders including stress and anxiety, as well as MDD (53,54). Further studies investigating GABAergic-mediated disinhibition and glutamatergic hyperactivity in MDD are needed. 


\section{CONCLUSION}

These results, coupled with previous findings investigating $5-\mathrm{HT}_{1 \mathrm{~A}}$ binding in the same cohort, suggest that subjects with greater serotonergic abnormality benefit most from serotonergic intervention. These findings move toward using PET to improve treatment selection. Follow-up PET studies would benefit from pre-/posttreatment scans, increased sample size, and comparison with nonserotonergic treatment and placebo (to determine whether this finding is specific to escitalopram). These measures will better allow us to validate the possibility of the amygdala and raphe as biomarkers of remission after $8 \mathrm{wk}$ of standardized SSRI treatment.

\section{DISCLOSURE}

No potential conflict of interest relevant to this article was reported.

\section{ACKNOWLEDGMENTS}

We thank Dr. Hao Chen from Stony Brook University and Drs. Jeff Miller and Todd Ogden from Columbia University for their comments and help in data acquisition and processing. We acknowledge the support from the Biostatistical Consulting Core at the School of Medicine, Stony Brook University.

\section{REFERENCES}

1. Kessler RC, Berglund P, Demler O, et al. The epidemiology of major depressive disorder: results from the National Comorbidity Survey Replication (NCS-R). JAMA. 2003;289:3095-3105.

2. Kessler RC, Chiu W, Demler O, Walters EE. Prevalence, severity, and comorbidity of 12-month DSM-IV disorders in the national comorbidity survey replication. Arch Gen Psychiatry. 2005;62:617-627.

3. Ferrari AJ, Charlson FJ, Norman RE, et al. Burden of depressive disorders by country, sex, age, and year: findings from the global Burden of Disease Study 2010. PLoS Med. 2013;10:e1001547.

4. Reddy MS. Depression: the disorder and the burden. Indian J Psychol Med. 2010;32:1-2.

5. Carvalho AF, Cavalcante JL, Castelo MS, Lima MCO. Augmentation strategies for treatment-resistant depression: a literature review. J Clin Pharm Ther. 2007;32: $415-428$.

6. Keller MB. Issues in treatment-resistant depression. J Clin Psychiatry. 2005; 66(suppl 8):5-12.

7. Fakhoury M. Revisiting the serotonin hypothesis: implications for major depressive disorders. Mol Neurobiol. 2016;53:2778-2786.

8. Manji HK, Drevets WC, Charney DS. The cellular neurobiology of depression. Nat Med. 2001;7:541-547.

9. Kambeitz JP, Howes OD. The serotonin transporter in depression: meta-analysis of in vivo and post mortem findings and implications for understanding and treating depression. J Affect Disord. 2015;186:358-366.

10. Miller JM, Hesselgrave N, Ogden RT, et al. Positron emission tomography quantification of serotonin transporter in suicide attempters with major depressive disorder. Biol Psychiatry. 2013;74:287-295.

11. Parsey RV, Hastings RS, Oquendo MA, et al. Lower serotonin transporter binding potential in the human brain during major depressive episodes. Am J Psychiatry. 2006;163:52-58.

12. Miller JM, Oquendo MA, Ogden RT, Mann JJ, Parsey RV. Serotonin transporter binding as a possible predictor of one-year remission in major depressive disorder. J Psychiatr Res. 2008;42:1137-1144.

13. Meyer JH. Imaging the serotonin transporter during major depressive disorder and antidepressant treatment. J Psychiatry Neurosci. 2007;32:86-102.

14. Murrough JW, Huang Y, Hu J, et al. Reduced amygdala serotonin transporter binding in posttraumatic stress disorder. Biol Psychiatry. 2011;70:1033-1038.

15. Szabo Z, McCann UD, Wilson AA, et al. Comparison of (+) $-{ }^{11} \mathrm{C}-\mathrm{McN} 5652$ and ${ }^{11} \mathrm{C}$-DASB as serotonin transporter radioligands under various experimental conditions. J Nucl Med. 2002;43:678-692.
16. Wilson AA, Ginovart N, Hussey D, Meyer J, Houle S. In vitro and in vivo characterisation of $\left[{ }^{11} \mathrm{C}\right]$-DASB: a probe for in vivo measurements of the serotonin transporter by positron emission tomography. Nucl Med Biol. 2002;29:509-515.

17. Miller JM, Hesselgrave N, Ogden RT, et al. Brain serotonin 1A receptor binding as a predictor of treatment outcome in major depressive disorder. Biol Psychiatry. 2013;74:760-767.

18. Bélanger MJ, Simpson NR, Wang T, Van Heertum RL, Mann JJ, Parsey RV. Biodistribution and radiation dosimetry of $\left[{ }^{11} \mathrm{C}\right] \mathrm{DASB}$ in baboons. Nucl Med Biol. 2004;31:1097-1102.

19. Ogden RT, Ojha A, Erlandsson K, Oquendo MA, Mann JJ, Parsey RV. In vivo quantification of serotonin transporters using $\left[{ }^{11} \mathrm{C}\right] \mathrm{DASB}$ and positron emission tomography in humans: modeling considerations. J Cereb Blood Flow Metab. 2007;27:205-217.

20. Talairech J, Tournoux P. Three-Dimensional Proportional System: An Approach of Cerebral Imaging-. Co-planar Stereotactic Atlas of the Human Brain. Thieme: New York, New York; 1988.

21. Duvernoy H. Surface, Three-Dimensional Sectional Anatomy and MRI: The Human Brain. Springer-Verlag: New York, New York; 1991.

22. Kates WR, Abrams MT, Kaufmann WE, Breiter SN, Reiss AL. Reliability and validity of MRI measurement of the amygdala and hippocampus in children with fragile X syndrome. Psychiatry Res. 1997;75:31-48.

23. Killiany RJ, Moss MB, Nicholson T, Jolesz F, Sandor T. An interactive procedure for extracting features of the brain from magnetic resonance images: the lobes. Hum Brain Mapp. 1997;5:355-363.

24. Schneck N, Miller JM, Delorenzo C, et al. Relationship of the serotonin transporter gene promoter polymorphism (5-HTTLPR) genotype and serotonin transporter binding to neural processing of negative emotional stimuli. J Affect Disord. 2016;190:494-498.

25. Strupp-Levitsky M, Miller JM, Rubin-Falcone H, et al. Lack of association between the serotonin transporter and serotonin 1A receptor: an in vivo PET imaging study in healthy adults. Psychiatry Res. 2016;255:81-86.

26. Parsey RV, Kent JM, Oquendo MA, et al. Acute occupancy of brain serotonin transporter by sertraline as measured by $\left[{ }^{11} \mathrm{C}\right] \mathrm{DASB}$ and positron emission tomography. Biol Psychiatry. 2006;59:821-828.

27. Ogden RT, Tarpey T. Estimation in regression models with externally estimated parameters. Biostatistics. 2006;7:115-129.

28. Zanderigo F, Ogden RT, Bertoldo A, Cobelli C, Mann JJ, Parsey RV. Empirical Bayesian estimation in graphical analysis: a voxel-based approach for the determination of the volume of distribution in PET studies. Nucl Med Biol. 2010;37:443-451.

29. Shapiro PA, Sloan RP, Deochand C, et al. Quantifying serotonin transporters by PET with $\left[{ }^{11} \mathrm{C}\right]-\mathrm{DASB}$ before and after interferon- $\alpha$ treatment. Synapse. 2014;68: 548-555.

30. Kugaya A, Sanacora G, Staley JK, et al. Brain serotonin transporter availability predicts treatment response to selective serotonin reuptake inhibitors. Biol Psychiatry. 2004;56:497-502.

31. Gryglewski G, Lanzenberger R, Kranz GS, Cumming P. Meta-analysis of molecular imaging of serotonin transporters in major depression. J Cereb Blood Flow Metab. 2014;34:1096-1103.

32. Lanzenberger R, Kranz GS, Haeusler D, et al. Prediction of SSRI treatment response in major depression based on serotonin transporter interplay between median raphe nucleus and projection areas. Neuroimage. 2012;63:874-881.

33. Sullivan GM, Ogden RT, Oquendo MA, et al. PET quantification of serotonin (1A) receptor binding in medication-free bipolar depression. Biol Psychiatry. 2009;66:223-230.

34. Stutzmann GE, LeDoux JE. GABAergic antagonists block the inhibitory effects of serotonin in the lateral amygdala: a mechanism for modulation of sensory inputs related to fear conditioning. J Neurosci. 1999;19:RC8.

35. Drevets WC. Neuroimaging abnormalities in the amygdala in mood disorders. Ann N Y Acad Sci. 2003;985:420-444.

36. Sheline YI, Barch DM, Donnelly JM, Ollinger JM, Snyder AZ, Mintun MA. Increased amygdala response to masked emotional faces in depressed subjects resolves with antidepressant treatment: an fMRI study. Biol Psychiatry. 2001;50:651-658.

37. Murphy SE, Norbury R, O'Sullivan U, Cowen PJ, Harmer CJ. Effect of a single dose of citalopram on amygdala response to emotional faces. Br J Psychiatry. 2009; 194:535-540.

38. Inoue $\mathrm{T}, \mathrm{Li} \mathrm{XB}$, Abekawa $\mathrm{T}$, et al. Selective serotonin reuptake inhibitor reduces conditioned fear through its effect in the amygdala. Eur J Pharmacol. 2004;497: 311-316.

39. Cheng LL, Wang SJ, Gean PW. Serotonin depresses excitatory synaptic transmission and depolarization-evoked $\mathrm{Ca} 2+$ influx in rat basolateral amygdala via 5-HT1A receptors. Eur J Neurosci. 1998;10:2163-2172.

40. Savitz JB, Drevets WC. Imaging phenotypes of major depressive disorder: genetic correlates. Neuroscience. 2009;164:300-330. 
41. Gobbi G, Murphy DL, Lesch K-P, Blier P. Modifications of the serotonergic system in mice lacking serotonin transporters: an in vivo electrophysiological study. J Pharmacol Exp Ther. 2001;296:987-995.

42. Arango V, Underwood MD, Boldrini M, et al. Serotonin 1A receptors, serotonin transporter binding and serotonin transporter mRNA expression in the brainstem of depressed suicide victims. Neuropsychopharmacology. 2001;25:892-903.

43. Mann JJ, Huang YY, Underwood MD, et al. A serotonin transporter gene promoter polymorphism (5-HTTLPR) and prefrontal cortical binding in major depression and suicide. Arch Gen Psychiatry. 2000;57:729-738.

44. Arango V, Underwood MD, Gubbi AV, Mann JJ. Localized alterations in pre- and postsynaptic serotonin binding sites in the ventrolateral prefrontal cortex of suicide victims. Brain Res. 1995;688:121-133.

45. Perry EK, Marshall EF, Blessed G, Tomlinson BE, Perry RH. Decreased imipramine binding in the brains of patients with depressive illness. Br J Psychiatry. 1983;142:188-192.

46. Reimold M, Batra A, Knobel A, et al. Anxiety is associated with reduced central serotonin transporter availability in unmedicated patients with unipolar major depression: a [11C]DASB PET study. Mol Psychiatry. 2008;13: 606-613, 557.

47. Siegle GJ, Steinhauer SR, Thase ME, Stenger VA, Carter CS. Can't shake that feeling: event-related fMRI assessment of sustained amygdala activity in response to emotional information in depressed individuals. Biol Psychiatry. 2002;51: 693-707.

48. Chen $\mathrm{CH}$, Suckling J, Ooi C, et al. Functional coupling of the amygdala in depressed patients treated with antidepressant medication. Neuropsychopharmacology. 2008;33:1909-1918.

49. Blier P, De Montigny C. Electrophysiological investigations on the effect of repeated zimelidine administration on serotonergic neurotransmission in the rat. J Neurosci. 1983;3:1270-1278.

50. Bhagwagar Z, Murthy N, Selvaraj S, et al. 5-HTT binding in recovered depressed patients and healthy volunteers: a positron emission tomography study with $\left[{ }^{11}\right.$ C]DASB. Am J Psychiatry. 2007;164:1858-1865.

51. Nuss P. Anxiety disorders and GABA neurotransmission: a disturbance of modulation. Neuropsychiatr Dis Treat. 2015;11:165-175.

52. Pehrson AL, Sanchez C. Altered $\gamma$-aminobutyric acid neurotransmission in major depressive disorder: a critical review of the supporting evidence and the influence of serotonergic antidepressants. Drug Des Devel Ther. 2015;9:603-624.

53. Sanacora G, Treccani G, Popoli M. Towards a glutamate hypothesis of depression: an emerging frontier of neuropsychopharmacology for mood disorders. Neuropharmacology. 2012;62:63-77.

54. Mathews DC, Henter ID, Zarate CA. Targeting the glutamatergic system to treat major depressive disorder: rationale and progress to date. Drugs. 2012;72: 1313-1333. 